\title{
Comparison of estimated energy requirements using predictive equations with total energy expenditure measured by the doubly labelled water method in acute spinal cord injury
}

\author{
Katherine J. Desneves ${ }^{1} \cdot$ Maya G. Panisset ${ }^{2} \cdot$ Jillian Rafferty $^{1} \cdot$ Helena Rodi $^{1} \cdot$ Leigh C. Ward $^{3} \cdot$ Andrew Nunn $^{4}$ • \\ Mary P. Galea $\mathbb{B}^{2,4}$
}

Received: 16 August 2018 / Revised: 1 December 2018 / Accepted: 18 January 2019 / Published online: 6 February 2019

(c) International Spinal Cord Society 2019

\begin{abstract}
Study design Prospective, observational

Objectives To evaluate agreement between a reference method (doubly labelled water, DLW) of total energy expenditure (TEE) and published equations for estimating energy requirements in acute spinal cord injury (SCI).

Setting Victoria, Australia

Methods Twenty participants (18 male) within 8 weeks of traumatic SCI completed DLW, anthropometric and dietary intake assessments. Energy requirements were predicted using Harris-Benedict, Schofield, Henry, Nelson, Buchholz and Chun equations, multiplied by a combined activity and stress factor of 1.3 , and the ratio method (kJ/kg body weight). Fatfree mass (FFM) and fat mass (FM) were calculated from TBW-derived DLW and from bioelectrical impedance spectroscopy (BIS).

Results Median time since injury was 41 days. Median TEE was 9.1 MJ. Fair agreement was found between TEE and predicted energy requirements for the Chun $\left(r_{c}=0.39\right)$, the Harris-Benedict equation $\left(r_{c}=0.30\right)$, the ratio method $\left(r_{c}=\right.$ $0.23)$ and the Buchholz $\left(r_{c}=0.31\right)$ and Nelson equations $\left(r_{c}=0.35\right)$, which incorporate measures of FFM and/or FM. Other equations showed weak concordance with DLW. When two hypermetabolic patients were removed, agreement between TEE and predicted energy requirements using the Buchholz equation increased to substantial $\left(r_{c}=0.72\right)$ and using the Nelson $\left(r_{c}=0.53\right)$ and Chun equations $\left(r_{c}=0.53\right)$ increased to moderate. The Buchholz equation had the smallest limits of agreement (-2.4-2.3 MJ/d).

Conclusion The population-specific Buchholz equation that incorporates FFM, predicted from either BIS or DLW, demonstrated the best agreement in patients with acute SCI.

Sponsorship The study was funded by grants from the Institute for Safety, Compensation and Recovery Research (ISCRR Project \# NGE-E-13-078) and Austin Medical Research Foundation. M Panisset was supported by an Australian Postgraduate Award.
\end{abstract}

Katherine J. Desneves

kate.desneves@austin.org.au

1 Department of Nutrition and Dietetics, Austin Health, Heidelberg, VIC 3084, Australia

2 Department of Medicine, Royal Melbourne Hospital, The University of Melbourne, Parkville, VIC 3010, Australia

3 School of Chemistry and Molecular Biosciences, The University of Queensland, St Lucia, QLD 4072, Australia

4 Victorian Spinal Cord Service, Austin Health, Heidelberg, VIC 3084, Australia

\section{Introduction}

Accurate assessment of energy needs is important to prevent under and over-nutrition and their associated morbidities $[1,2]$. The metabolic response to acute SCI within the first 7 weeks is not well understood, although nitrogen loss and decreased protein synthesis, whole-body energy stores and lean muscle mass have been reported. Despite the importance of appropriate nutrition, few studies have examined energy requirements in acute SCI [3-8].

While metabolic demand may be heightened during the initial catabolic phase, energy requirements during rehabilitation and chronic phases gradually decline to below prior 
to injury or those of controls $[9,10]$. The transition from the catabolic phase to decreased energy needs is not well defined although resting energy expenditure (REE) has been reported to decrease after 10 weeks [4]. Energy needs may be affected by multiple factors including level [8] and completeness of injury [11], body composition [9, 12], presence of infection or pressure injuries [13] and activity [11]. Accurate measures of energy expenditure are expensive and clinically practical methods have not been validated in this patient population.

Indirect calorimetry is recommended in SCI [3] but is often unavailable in the clinical setting. Predictive equations derived from able-bodied populations are used to estimate REE and individually adjusted by multiplying REE by activity and/or stress factors not specific for the SCI population to predict total energy expenditure (TEE) $[14,15]$. Indirect calorimetry measures of energy expenditure in individuals with chronic SCI have been compared with estimates of energy expenditure using the HarrisBenedict equation $[8,10,13]$, which incorporates age, sex, weight and height but various stress and activity factors have been used and some authors failed to specify factors, making comparisons difficult [6]. There is a lack of evidence on the most valid predictive equation and which activity and/or stress factors are appropriate when estimating TEE in people with acute SCI [16]. One study found a significant correlation between measured energy expenditure and predicted TEE in acute SCI (4 weeks post injury), using the Harris-Benedict equation, incorporating a stress factor of 1.2 and an activity factor of 1.1 [7]. In males $\geq 8$ weeks post injury, measured values were $96 \%$ of those predicted using the Harris-Benedict equation with an activity factor of 1.2 [13]. Others have reported predictions based on the Harris-Benedict equation, using an activity factor of 1.2 , overestimate REE by $28 \%$ in people with SCI [8].

The Schofield [17] and Henry [18] equations, based on body weight and age, are also used to predict energy requirements. Studies in individuals with chronic SCI report that the Schofield equation significantly overestimated basal metabolic rate (BMR) and REE [19, 20].

Altered body composition may affect energy expenditure in SCI [21]. A correlation between fat-free mass (FFM) and REE in participants with chronic paraplegia lead to the development of a population-specific prediction equation for REE, including age, sex, height and FFM as predictor variables [19]. This equation was recently cross-validated and found to closely predict REE in a sample of 30 individuals with paraplegia and eight with tetraplegia [22]. Others have reported excellent agreement between measured BMR using indirect calorimetry and BMR estimated using the Cunningham equation [23] and newly developed population-specific equations $[20,24]$ that include FFM, with or without anthropometric measurements [20]. Given the lack of evidence regarding TEE in the acute phase post-injury and the well-established changes that occur in body composition, further investigation of prediction equations, including those that estimate REE based on FFM and fat mass (FM), are warranted [19, 24, 25].

The doubly labelled water (DLW) technique is the reference method of TEE [26]. DLW also quantifies total body water, and thereby FFM and FM. The aim of this study was to evaluate the validity of published predictive equations used in clinical practice to estimate energy requirements in acute SCI, against the reference method, DLW, and to test the hypothesis that equations based on FFM would be more accurate predictors of metabolic demands in acute SCI, compared to equations based on height and weight.

\section{Methods}

\section{Participants}

Patients with SCI who had sustained an acute traumatic complete (AIS A) or incomplete SCI (AIS B, C, D) above T12, according to the American Spinal Injury Association (ASIA) Impairment Scale (AIS) criteria, were screened for eligibility. 'Acute' was defined as within 8 weeks postSCI, since nutritional depletion based on anthropometry $[1,4]$, biochemistry [1] and negative nitrogen balance [1] has been reported within this timeframe. Participants were medically stable, able to provide informed (written or witnessed, verbal) consent and medically and surgically cleared to participate. Participants less than 18 years, with multiple trauma or intercurrent illness, in ICU or ventilator-dependent, pregnant or breastfeeding were excluded.

\section{Standard care}

This study was observational. All participants received standard care including standard hospital diet with or without oral nutrition support, regular passive movement of the paralysed limbs, strategies for bed mobility, transfers, wheelchair mobility skills and standing and walking with or without assistive devices.

\section{Anthropometry}

Body weight was measured to the nearest $100 \mathrm{~g}$ on either Gludmann or Wedderburn Rinstrum R320 hoist scales or Wedderburn Model No. 2100 platform scales the day before study commencement. Supine length was measured to the nearest $0.5 \mathrm{~cm}$ using portable metal bookends and a rigid tape measure. 
Estimated energy intake (EEI) and estimated protein intake assessment

A dietitian completed 3-day, 24-h recalls of all food and fluids consumed at the beginning and end of the study period. Food recalls were analysed using Foodworks dietary analysis software (Xyris Software, Australia, 2007 Version 5).

\section{Total energy expenditure}

The DLW technique was used to measure TEE [27]. Baseline (Day 0) urine samples were obtained prior to ingestion of the labelled water to determine background isotope enrichment. DLW $\left(99 \%{ }^{2} \mathrm{H}_{2} \mathrm{O}\right.$ (deuterium) and $97 \%$ ${ }^{18} \mathrm{O}$ in solution), prepared by the hospital pharmacy, was administered orally at a dose rate of $0.2 \mathrm{~g} / \mathrm{kg}$; the precise dose amount being determined gravimetrically [27].

Duplicate urine samples were collected on days 1, 2, 5, $6,8,9,12$ and 13 post-dose. Urine samples were taken from the catheter port via a syringe following $30 \mathrm{~min}$ clamping of the catheter, stored at $-20{ }^{\circ} \mathrm{C}$ and shipped to the Children's Nutrition Research Centre at the University of Queensland for isotope analysis. Four post-dose samples (days 1,2,13 and 14) were analysed to determine isotopic enrichments using a Dual Inlet Isoprime isotope ratio mass spectrometer (Isoprime, Manchester, UK). Results were expressed relative to the international standard, Vienna Standard Mean Ocean Water. Dilution spaces for both deuterium and oxygen-18 were calculated according to standard equations [28]. Rate constants were determined via the multipoint method with the production rate of $\mathrm{CO}_{2}$ calculated as the difference between the elimination rates of deuterium and oxygen-18, accounting for isotopic fractionation [29]. Oxygen consumption was determined by assuming a respiratory quotient of $0.85[2$, 29], and TEE was calculated according to the abbreviated Weir equation [30].

\section{Body composition}

$\mathrm{FFM}_{\mathrm{DLW}}$ and $\mathrm{FM}_{\mathrm{DLW}}$ were calculated from TBW derived from deuterium elimination rates by assuming a hydration fraction for FFM of 0.732 [31]. FM $_{\text {BIA }}$ was also predicted from whole body impedance measurements as described previously [32] using the prediction equation of Kocina and Heyward [33]. Fat mass predicted from impedance measurements $\left(\mathrm{FM}_{\mathrm{BIA}}\right)$ was calculated as the difference between body weight and FFM $\mathrm{BIA}_{\text {. }}$

\section{Estimation of energy requirements}

The predictive equations used for comparison were Schofield [17], Harris and Benedict [34] and Henry [18]. TEE was also estimated using the ratio method $(135 \mathrm{~kJ} / \mathrm{kg}$ [35]) which was current clinical practice. For participants with a BMI > 30, body weight was adjusted to ideal weight at BMI of 25 [36]. FFM and FM, calculated from deuterium elimination rates or bioelectrical impedance spectroscopy (BIS), were used to estimate REE in the Nelson [25], RMR in the Buchholz [19] and BMR in the Chun [24] equations. Where original equations were formulated in $\mathrm{Kcal}$, data were converted to $\mathrm{kJ}$ using the conversion factor $4.18 \mathrm{~kJ} / \mathrm{Kcal}$. Equations are presented in Table 1. REE/RMR/BMR was multiplied by a stress factor of 1.2 plus an activity factor of 1.1 recommended by Barco et al. [7]. to estimate TEE.

\section{Estimation of protein requirements}

Protein requirements were estimated using $1.35 \mathrm{~g} / \mathrm{kg}$ body weight as per Nutrition and Dietetics Department clinical guidelines (unpublished).

\section{Statistical analysis}

Statistical analyses were performed using Medcalc (MedCalc Software bvba, Belgium). Data were normally distributed (Kolmogorov-Smirnov test) and descriptive statistics are expressed as mean $\pm \mathrm{SD}$, median with interquartile range (IQR) and overall range. The relationship between methods was assessed using Pearson's correlation $\left(r_{p}\right)$. Lin's concordance coefficient $\left(r_{c}\right)$ was used to evaluate concordance, precision and accuracy of estimated energy requirements (EER) from each method compared to TEE from DLW. Strength of agreement used the following classification: $<0.00=$ poor, $0.00-0.20=$ slight, $0.21-0.40$ $=$ fair, $0.41-0.60=$ moderate, $0.61-0.80=$ substantial, and 0.81-1.00 = almost perfect agreement [37].

Limits of agreement analysis (LOA) was performed as described by Bland and Altman [38].

Outliers were identified by calculating the difference between measured and expected TEE using the most accurate predictive equation and testing for outliers using the Generalised Extreme Studentized Deviate method, and an alpha level of 0.05 .

\section{Results}

\section{Participant characteristics}

Table 2 depicts participant $(N=20)$ and injury characteristics. Median age was 42.5 years (IQR 24-61). Median time since injury was 41 days (IQR 28-48). Median BMI at baseline was 24.7 (IQR 21-28). Five participants had complete injuries (two tetraplegia) and fifteen had incomplete injuries (14 tetraplegia). Participants were Caucasian 
Table 1 Equations evaluated for the estimation on TEE in individuals with acute spinal cord injury

\begin{tabular}{|c|c|c|}
\hline Source & Age range & Equation \\
\hline \multirow[t]{6}{*}{ Schofield [20] (MJ/d) } & \multirow[t]{2}{*}{$18-30$} & Males $\mathrm{BMR}=(0.063 \times \mathrm{W})+2.896$ \\
\hline & & Females BMR $=(0.062 \times \mathrm{W})+2.036$ \\
\hline & \multirow[t]{2}{*}{$30-60$} & Males $\mathrm{BMR}=(0.048 \times \mathrm{W})+3.653$ \\
\hline & & Females $\mathrm{BMR}=(0.034 \times \mathrm{xW})+3.538$ \\
\hline & \multirow[t]{2}{*}{$>60$} & Males $\mathrm{BMR}=(0.049 \mathrm{x} \mathrm{W})+2.459$ \\
\hline & & Females $\mathrm{BMR}=(0.038 \times \mathrm{W})+2.755$ \\
\hline \multirow[t]{6}{*}{ Henry [21] (MJ/d) } & \multirow[t]{2}{*}{$18-30$} & Males $\mathrm{BMR}=(0.0669 \times \mathrm{x})+2.28$ \\
\hline & & Females $\mathrm{BMR}=(0.0546 \mathrm{x} \mathrm{W})+2.33$ \\
\hline & \multirow[t]{2}{*}{$30-60$} & Males $\mathrm{BMR}=(0.0592 \times \mathrm{W})+2.48$ \\
\hline & & Females $\mathrm{BMR}=(0.0407 \times \mathrm{x} \mathrm{W})+2.90$ \\
\hline & \multirow[t]{2}{*}{$60+$} & Males $\mathrm{BMR}=(0.0563 \times \mathrm{W})+2.15$ \\
\hline & & Females $\mathrm{BMR}=(0.0424 \times \mathrm{x})+2.38$ \\
\hline \multicolumn{2}{|l|}{ Harris-Benedict [34] } & Males $\mathrm{BMR}=278+(57.5 \times \mathrm{x} \mathrm{W})+(20.9 \mathrm{xH})-(28.3 \times \mathrm{A})$ \\
\hline \multicolumn{2}{|l|}{$(\mathrm{kJ} / \mathrm{d})$} & Females $\mathrm{BMR}=2741+(40 \times \mathrm{W})+(7.7 \times \mathrm{H})-(19.6 \times \mathrm{A})$ \\
\hline \multicolumn{2}{|l|}{ Ratio $(\mathrm{kJ} / \mathrm{d})$} & $\mathrm{TEE}=135 \mathrm{~kJ} / \mathrm{kg}$ \\
\hline \multicolumn{2}{|l|}{ Buchholz et al. [22]. (kJ/d) } & $\mathrm{RMR}=10682-1238($ ln age $)-521($ sex $)-24($ height $)+87(\mathrm{FFM})$ \\
\hline \multicolumn{2}{|l|}{ Nelson et al. [27]. (kJ/d) } & $\mathrm{REE}=(108 \times \mathrm{FFM})+(16.9 \times \mathrm{FM})$ \\
\hline \multicolumn{2}{|l|}{ Chun et al. [26]. (kcal/d) } & $\mathrm{BMR}=24.5 \times \mathrm{FFM}+244.4$ \\
\hline
\end{tabular}

BMR is a measurement made using indirect calorimetry under highly standardised and controlled conditions and is frequently used interchangeably in the literature with resting metabolic rate (RMR) or resting energy expenditure (REE) which are any other measurements of resting energy metabolism under conditions that approximate those of BMR

$W$ weight in $\mathrm{kg}, H$ height in $\mathrm{cm}, A$ age in years, FFM and FM in $\mathrm{kg}, R M R$ resting metabolic rate, $B M R$ basal metabolic rate, $R E E$ resting energy expenditure, TEE total energy expenditure

\begin{tabular}{|c|c|c|c|c|}
\hline Variable & Mean \pm SD & Median & (Q1, Q3) & Range \\
\hline Age (years) & $43.2 \pm 19.6$ & 42.5 & $24.5-60.5$ & $18-82$ \\
\hline Days post injury & & 41 & $28-48$ & $17-75$ \\
\hline Height (cm) & $175.8 \pm 10.3$ & 177.0 & $169.0-181.0$ & $153.5-198.0$ \\
\hline Weight (kg) & $79.5 \pm 16.7$ & 78.2 & $65.9-87.9$ & $55.4-127.2$ \\
\hline BMI $\left(\mathrm{kg} / \mathrm{m}^{2}\right)$ & $25.9 \pm 6.4$ & 24.6 & $21.7-27.9$ & $18.0-47.3$ \\
\hline $\mathrm{FFM}_{\mathrm{DLW}}(\mathrm{kg}$, from DLW) & $58.4 \pm 9.9$ & 55.6 & $51.7-64.5$ & $39.3-78.3$ \\
\hline $\mathrm{FM}_{\text {DLW }}(\mathrm{kg}$, from DLW) & $21.1 \pm 10.5$ & 20.0 & $11.6-27.8$ & $8.4-51.3$ \\
\hline $\mathrm{FFM}_{\mathrm{BIA}}(\mathrm{kg}$, from BIA $)$ & $56.9 \pm 9.8$ & 55.6 & $50.8-61.7$ & $41.5-78.7$ \\
\hline $\mathrm{FM}_{\mathrm{BIA}}(\mathrm{kg}$, from BIA $)$ & $21.8 \pm 10.7$ & 20.3 & $12.7-28.7$ & $9.7-52.0$ \\
\hline TEE (MJ/day) & $9.85 \pm 3.24$ & 9.05 & $8.18-11.38$ & $5.86-19.60$ \\
\hline Injury characteristics & & & Severity & $\mathrm{N}$ \\
\hline \multirow[t]{4}{*}{ High tetraplegia $(\mathrm{C} 1-\mathrm{C} 4) n=12$} & & & AIS A & 1 \\
\hline & & & AIS B & 6 \\
\hline & & & AIS C & 3 \\
\hline & & & AIS D & 2 \\
\hline \multirow[t]{3}{*}{ Low tetraplegia $(\mathrm{C} 5-\mathrm{C} 8) n=4$} & & & AIS A & 1 \\
\hline & & & AIS B & 2 \\
\hline & & & AIS C & 1 \\
\hline Paraplegia (T1-L5) $n=4$ & & & AIS A & 3 \\
\hline
\end{tabular}

AIS ASIA impairment scale, BMI body mass index, FFM fat free mass, FM fat mass, TEE total energy expenditure
Table 2 Participant and injury characteristics 
Table 3 Agreement between TEE using DLW and estimated energy requirements using predictive equations for all participants $(n=20)$

\begin{tabular}{|c|c|c|c|c|c|c|c|}
\hline Prediction method & $\begin{array}{l}\text { Weight } \\
\text { adjustment }\end{array}$ & TEE (MJ/day) & $\begin{array}{l}\text { Concordance coefficient, } r_{c} \\
(95 \% \mathrm{CI})\end{array}$ & $\begin{array}{l}\text { Pearson } \\
\text { coefficient, } r_{c}\end{array}$ & $\begin{array}{l}\text { Bias (DLW- } \\
\text { predicted) }\end{array}$ & $\begin{array}{l}\text { Limits of } \\
\text { Agreement } \\
(\mathrm{MJ} / \text { day })\end{array}$ & $\begin{array}{l}\text { Absolute } \\
\text { percentage } \\
\text { error }\end{array}$ \\
\hline DLW & & $9.85 \pm 3.24$ & & & & & \\
\hline \multirow[t]{2}{*}{ Schofield [20] } & - & $9.43 \pm 1.32$ & $0.18(-0.12$ to 0.46$)$ & 0.27 & 0.42 & -5.7 to 6.7 & 12.4 \\
\hline & + & $9.30 \pm 1.25$ & $0.20(-0.12$ to 0.45$)$ & 0.30 & 0.55 & -5.5 to 6.7 & 11.4 \\
\hline \multirow[t]{2}{*}{ Henry [21] } & - & $9.30 \pm 1.32$ & $0.18(-0.12$ to 0.46$)$ & 0.27 & 0.55 & -5.6 to 6.8 & 12.7 \\
\hline & + & $9.15 \pm 1.24$ & $0.20(0.08$ to 0.46$)$ & 0.32 & 0.70 & -5.3 to 6.8 & 12.6 \\
\hline \multirow[t]{2}{*}{ Harris-Benedict [34] } & - & $9.42 \pm 1.47$ & $0.30(-0.02$ to 0.56$)$ & 0.41 & 0.33 & -5.4 to 6.3 & 12 \\
\hline & + & $9.30 \pm 1.45$ & $0.31(0.00$ to 0.57$)$ & 0.31 & 0.55 & -5.3 to 6.8 & 10.7 \\
\hline \multirow[t]{2}{*}{ Ratio Method } & - & $10.73 \pm 2.26$ & $0.23(-0.18$ to 0.57$)$ & 0.26 & -0.88 & -7.6 to 5.9 & 27.2 \\
\hline & + & $10.47 \pm 2.18$ & $0.27(0.14$ to 0.60$)$ & 0.30 & -0.62 & -7.1 to 5.9 & 25 \\
\hline Buchholz et al. [22]. & - & $9.05 \pm 1.34$ & $0.31(0.03$ to 0.55$)$ & 0.47 & 0.80 & -4.8 to 6.5 & 11.2 \\
\hline Nelson et al. [27] & - & $8.67 \pm 1.49$ & 0.35 (0.07 to 0.58$)$ & 0.53 & 1.18 & -4.2 to 6.7 & 8.6 \\
\hline Chun et al. [26] & - & $9.10 \pm 1.32$ & $0.39(0.13$ to 0.60$)$ & 0.59 & 0.75 & -4.5 to 6.0 & 11.5 \\
\hline
\end{tabular}

males except for one Asian female and one Caucasian female.

Eight participants mobilised in power wheelchairs, three in manual wheelchairs and five used both. Of those five, one participant was walking with assistive devices, one used a combination of manual wheelchair and walking with assistive devices and one was using a combination of power wheelchair and walking up to $10 \mathrm{~m}$ with supervision. The remaining participant became septic, rested in bed and was transferred to another hospital on day 1 of the study however ethics clearance allowed ongoing data collection. Spasticity was recorded in four participants; two were prescribed baclofen, the level of spasticity did not impact on the function of the other two individuals.

Four participants became febrile during the study period, one developed hospital-acquired pneumonia and three urinary tract infections. A fifth participant became septic with a pelvic collection that required surgical intervention, and developed acute renal failure. All remained in the study.

Over the study period, participants lost a median of $0.8 \mathrm{~kg}$ (IQR - 2.0-0.30). Median estimated energy intake was 9.7 MJ (IQR 8.6-10.8 MJ), 107\% of measured TEE, and estimated protein intake was $101 \mathrm{~g} /$ day (IQR 92-116 g).

\section{Comparison of predicted energy requirements to total energy expenditure}

TEE and FFM were significantly correlated $(r=0.59, p=$ 0.01 ). Table 3 presents correlations, limits of agreement and absolute percentage error for all methods compared with TEE. Fair agreement was found between TEE and predicted energy requirements using the Buchholz [19] $\left(r_{c} 0.31\right.$; 95\% CI $0.03-$ 0.55), Nelson [25] $\left(r_{c} 0.35 ; 95 \%\right.$ CI 0.07-0.58) and Chun [24] $\left(r_{c} \quad 0.39 ; 95 \%\right.$ CI $\left.0.13-0.60\right)$ equations that incorporate measures of FFM $_{\text {DLW }}$ and/or FM DLW. Similarly, agreement using Harris-Benedict [34] $\left(r_{c} 0.3\right.$; 95\%CI: $\left.-0.02-0.56\right)$ and ratio methods $\left(r_{c} 0.23 ; 95 \% \mathrm{CI}-0.18-0.57\right)$ was fair, whereas the Schofield [17] $\left(r_{c} 0.18 ; 95 \%\right.$ CI: $\left.-0.12-0.46\right)$ and the Henry [18] equations $\left(r_{c} 0.18 ; 95 \% \mathrm{CI}:-0.12-0.46\right)$ showed only slight concordance with DLW measurements of TEE. Classification of agreement did not alter when adjusted body weight was used for participants with a BMI $>30$.

Figure 1 depicts LOA for agreement between TEE and energy requirements predicted by the various equations for all participants. The equations show varied bias $(-0.8$ to $1.2 \mathrm{MJ}$ ) and wide limits of agreement ( -7.6 to $6.8 \mathrm{MJ})$. The significant slope of the regression line indicates that there was systematic error in the estimates.

Figure 2 depicts Box and Whisker plot for the difference between measured and predicted TEE using the populationspecific Buchholz [19], Chun [24] and Nelson [25] equations. The combined injury and activity factor of 1.3 provided a close estimation of TEE for $90 \%$ of the sample.

Two patients were identified statistically as outliers. Review of clinical data determined that they were hypermetabolic compared to other participants. When their data was excluded from the analysis, agreement between TEE and predicted energy requirements using all three FFMbased prediction equations improved: Buchholz [19] $\left(r_{c}\right.$ $0.7295 \%$ CI 0.44-0.87) increased to substantial; Nelson [25] $\left(r_{c} 0.53 ; 95 \%\right.$ CI 0.14-0.78) and Chun [24] $\left(r_{c} 0.53\right.$; 95\% CI 0.16-0.77) increased to moderate (Table 4).

\section{Discussion}

This is the first study to evaluate agreement between predictive equations for estimating energy requirements in 
Fig. 1 Limits of agreement comparing TEE values derived from DLW and those predicted using various equations for all participants
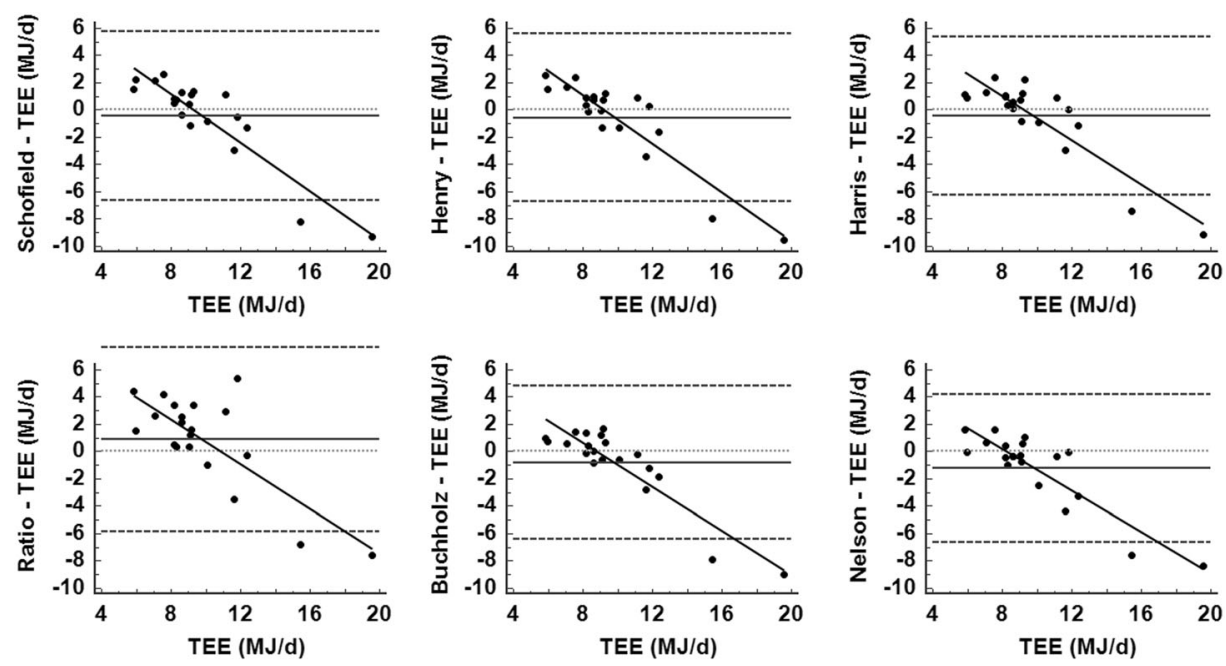

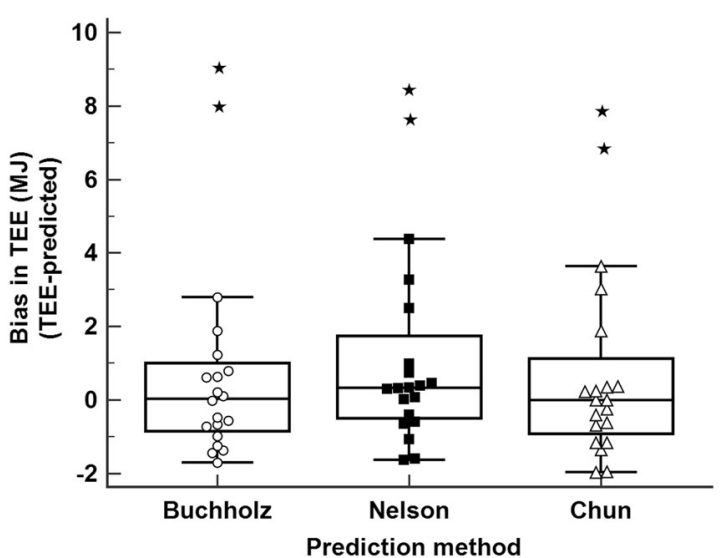

Fig. 2 Difference between TEE and energy requirements predicted using three FFM-based prediction equations

acute SCI with the DLW technique, an accepted reference method of TEE. The major finding of the study was that equations that include measures of body composition were the most accurate predictors of TEE. The populationspecific Buchholz equation [19], multiplied by a combined activity and stress factor of 1.3, suggested by Barco et al. [7], fitted $90 \%$ of the study sample. Two participants were statistical outliers, with measured energy requirements more than $4 \mathrm{MJ}$ greater than predicted using the Buchholz equation [19]. The outliers were both male, with C2 and C3 AIS $\mathrm{B}$ tetraplegia and mobilised in power wheelchairs. One regularly used functional electrical stimulation cycling exercise which may have increased activity-related energy expenditure. Whilst neither participant was febrile during the study period, the second outlier had intermittent lowand high-grade fevers secondary to a urinary tract infection one week prior to commencing the study and was extremely anxious. Hence the combined stress and activity factor of 1.3 was not appropriate in these cases, suggesting that activity and stress factors should be individualised.

TEE and FFM, irrespective of whether measured by deuterium dilution or predicted by BIS, were significantly correlated $(r=0.59 ; p=0.01)$ in the studied sample; a lower value than that seen for able-bodied individuals [10] but consistent with a study in individuals with paraplegia [19]. Hence FFM, not weight, is included in the Buchholz [19] and Chun [24] equations and FFM in addition to anthropometrics in the Nightingale [20] equation for individuals with chronic SCI.

As hypothesised, predictive equations developed in chronic SCI that include body composition measures, adjusted for stress and activity factors, demonstrated better agreement than simple height- and weight-based predictors. The agreement was classified as only fair for the entire sample, although this increased to substantial when outlying hypermetabolic participants were removed. The Buchholz [19] equation performed better than the Nelson [25] or Chun [24] equations exhibiting smaller bias and LOA (Table 4). This finding is consistent with a recent publication by Andersen et al., who also reported that the Buchholz et al., equation closely predicted REE in a varied sample of participants with paraplegia and tetraplegia [22]. The 
Table 4 Agreement between TEE using DLW and estimated energy requirements using FFM-based predictive equations excluding hypermetabolic participants

\begin{tabular}{|c|c|c|c|c|c|c|c|}
\hline Prediction method & $\begin{array}{l}\text { FFM } \\
\text { calculation }\end{array}$ & TEE (MJ/day) & $\begin{array}{l}\text { Concordance coefficient, } \\
r_{c}(95 \% \mathrm{CI})\end{array}$ & $\begin{array}{l}\text { Pearson } \\
\text { coefficient, } r_{p}\end{array}$ & $\begin{array}{l}\text { Bias (DLW- } \\
\text { predicted }\end{array}$ & $\begin{array}{l}\text { Limits of } \\
\text { Agreement } \\
\text { (MJ/day) }\end{array}$ & $\begin{array}{l}\text { Absolute } \\
\text { percentage } \\
\text { error }\end{array}$ \\
\hline DLW & & $8.99 \pm 1.87$ & & & & & \\
\hline Buchholz et al. [22] & $\mathrm{D}_{2} \mathrm{O}$ & $9.04 \pm 1.32$ & $0.72(0.44$ to 0.87$)$ & 0.76 & -0.05 & -2.4 to 2.3 & 9.8 \\
\hline Nelson et al. [27] & $\mathrm{D}_{2} \mathrm{O}$ & $8.56 \pm 1.43$ & $0.53(0.14$ to 0.78$)$ & 0.57 & 0.43 & -2.7 to 3.5 & 7.3 \\
\hline Chun et al. [26] & $\mathrm{D}_{2} \mathrm{O}$ & $8.98 \pm 1.23$ & $0.53(0.16$ to 0.77$)$ & 0.58 & 0.01 & -3.0 to 3.0 & 9.3 \\
\hline Buchholz et al. [22] & BIA & $8.97 \pm 1.25$ & $0.71(0.44$ to 0.86$)$ & 0.76 & 0.02 & -2.4 to 2.4 & 11.8 \\
\hline Nelson et al. [27] & BIA & $8.48 \pm 1.33$ & $0.52(0.14$ to 0.76$)$ & 0.58 & 0.51 & -2.5 to 3.5 & 9.6 \\
\hline Chun et al. [26] & BIA & $8.90 \pm 1.30$ & $0.52(0.17$ to 0.75$)$ & 0.59 & 0.09 & -2.8 to 3.0 & 8.8 \\
\hline
\end{tabular}

differences in agreement between these equations in the current study might be due to differences in ethnicity and levels of injury of participants between studies; in the present study all participants except one were Caucasian and the majority had tetraplegia with a mean FFM of $58.4 \mathrm{~kg}$. Chun et al. [24]. included only East Asian participants with both tetraplegia and paraplegia and mean FFM of $42.1 \mathrm{~kg}$ while Buchholz et al. [19]. included only those with paraplegia (mean FFM of $69.2 \mathrm{~kg}$ ).

Predictive equations developed in healthy individuals, although adjusted for SCI stress and activity, showed poor predictive value in the present acute SCI sample. The Henry [18] and Schofield [17] equations demonstrated only weak agreement, while only fair agreement was found for the HarrisBenedict equation [34]. The ratio method, whilst attractive due to its simplicity, gave the least accurate estimate of TEE, with the largest limits of agreement. These findings are consistent with another study in adult hospital patients that found the percentage of accurately predicted REE ( $\pm 10 \%$ of measured) was low, ranging from 8-49\% in all equations [39].

Most other studies quantifying energy expenditure in SCI included participants with chronic SCI. Differences in timeframe and injury characteristics make comparison difficult or inappropriate and findings not generalisable to acute SCI. Only three studies [6-8], that measured REE within or close to the first eight weeks post-SCI provide comparative results. One study with a similar timeframe post-injury (mean 65.5 days) and similar proportion of individuals with tetraplegia and paraplegia to the current study found the Harris-Benedict equation, multiplied by an activity factor of 1.2, overestimated REE by up to $30 \%$ [8]. Conversely, Barco et al. [7]. reported measured TEE was 95-100\% of predicted energy expenditure using the HarrisBenedict equation (activity factor 1.1, stress factor 1.2) in 11 male mechanically-ventilated patients with tetraplegia 4 weeks post-injury; the level and severity of SCI were not described. Aquilani et al. [13]. found measured REE was $96 \%$ of predicted by the Harris-Benedict equation in ten males with complete paraplegia ( $\geq 2$ months post-injury, with similar injury and severity levels) although REE may have been elevated due to the presence of pressure sores and urinary tract infections.

In individuals with chronic, complete SCI, level of injury relates to BMR; the higher the level of the injury the lower the BMR $[6,11]$, due to the greater degree of denervation, inactivity and subsequent muscle atrophy [11]. Similarly, decreased FFM is associated with higher, more complete injuries [40]. In contrast, the two participants in the current study with the highest energy requirements (both statistical outliers), 15.5 and 19.7 MJ respectively, had C2 and C3 AIS B tetraplegia and lost 2 and $6.8 \mathrm{~kg}$ respectively over the 2-week study period. Unfortunately, small participant numbers in the current study prevented statistical analysis by level and severity of injury.

The small sample size and heterogeneous population in regards to level of injury, AIS classification, activity and sex are limitations of the current study and may limit the generalisability of the observations. Unfortunately, due to the high cost of DLW, studies with large sample sizes are impracticable [28] and the number of participants was comparable to other studies. However, despite the heterogeneity, an equation that can be used clinically to more accurately predict energy requirements was validated against a reference method. The heterogeneity of the study participants is representative of the SCI population and reflects the challenges in estimating energy requirements in clinical practice. The paucity of participants at any single centre will require multi-centre studies in the future to provide the larger numbers of patients required to draw definitive conclusions regarding energy metabolism in those with SCI. This would enable confounding factors such as level and severity of injury, sex, hydration status, spasticity and pressure injuries to be addressed. Future research should also focus on developing spinal cord injury-specific activity and stress factors and validating a new equation that includes anthropometry as well as FFM [20].

In conclusion, our DLW study is the first to compare predictive equations for estimating energy requirements 
with measured TEE in acute SCI. TEE was significantly correlated with FFM, with the Buchholz FFM-based equation [19], using a combined activity and stress factor of 1.3 , being the best performing and as suggested by Andersen et al. [22]. should be considered for use in clinical practice. FFM derived from BIS or DLW can be used in this equation. BIS may be the more practical alternative owing to its simplicity of use and lower cost [32]. Identification of hypermetabolism is important in order to individualise stress factors and could be the focus of future research.

Acknowledgements The authors would like to acknowledge the contributions of the participants and their families, the spinal liaison officers and the dietetics department for their support and to thank Professor Peter Davies from the University of Queensland for the isotope analysis.

Funding The study was funded by grants from the Institute for Safety, Compensation and Recovery Research (ISCRR Project \# NGE-E-13078) and Austin Medical Research Foundation. M Panisset was supported by an Australian Postgraduate Award.

Authors contributions KJD participated in study design, contributed to grant procurement, performed data collection, performed data entry, drafted the manuscript. MGP participated in study design, contributed to grant procurement, performed data collection, performed data entry, contributed to statistical analyses, contributed to manuscript preparation. JR participated in study design, contributed to grant procurement, performed data collection, performed data entry, contributed to manuscript preparation. HR participated in study design, contributed to grant procurement, performed data collection, performed data entry, contributed to manuscript preparation. LCW advised on data collection protocol, performed data quality assurance, contributed to statistical analyses and manuscript preparation. AN provided medical oversight, commented on the manuscript. MPG developed the concept for and designed the study, contributed to grant procurement and manuscript preparation

Data availability The datasets generated and/or analysed during the current study are available from the corresponding author on reasonable request.

\section{Compliance with ethical standards}

Conflict of interest Author Ward consults to Impedimed Ltd. The remaining authors declare that they have no conflict of interest.

Ethical approval Ethical approval for this study was obtained from the Austin Health Human Research Ethics Committee (H2013/05117) and all applicable institutional and governmental regulations concerning the ethical use of human volunteers were followed.

Publisher's note: Springer Nature remains neutral with regard to jurisdictional claims in published maps and institutional affiliations.

\section{References}

1. Kaufman HH, Rowlands BJ, Stein DK, Kopaniky DB, Gildenberg PI. General metabolism in patients with acute paraplegia and quadriplegia. Neurosurgery. 1985;16:309-13.
2. McLave S, Lowen C, Kleber M, McConnell J, Jung L, Goldsmith L. Clinical use of the respiratory quotient obtained from indirect calorimetry. J Parenter Enter Nutr. 2003;27:21-26.

3. Nevin AN, Steenson J, Vivanti A, Hickman IJ. Investigation of measured and predicted resting energy needs in adults after spinal cord injury: a systematic review. Spinal Cord. 2016;54:248-53.

4. Felleiter P, Krebs J, Haeberli Y, Schmid W, Tesini S, Perret C, et al. Post-traumatic changes in energy expenditure and body composition in patients with acute spinal cord injury. J Rehabil Med. 2017;49:579-84.

5. Mawatari M, Higo T, Tsutsumi Y, Shigematsu M, Hotokebuchi T, Moriyama S, et al. Total energy expenditure and energy intake in pre-school child: a comparison. J Parenter Enter Nutr. 1985; 25:277-82.

6. Kolpek JH, Ott LG, Record KE, Rapp RP, Dempsey R, Tibbs P. Comparison of urinary urea nitrogen excretion and measured energy expenditure in spinal cord injury and nonsteroid-treated severe head trauma patients. J Parenter Enter Nutr. 1989;13:277-80.

7. Barco K, Smith RA, Peerless JR, Plaisier BR, Chima CS. Energy expenditure assessment and validation after acute spinal cord injury. Nutr Clin Pract. 2002;17:309-13.

8. Cox SAR, Weiss SM, Posuniak EA, Worthington P, Prioleau M, Heffley G. Energy expenditure after spinal cord injury: an evaluation of stable rehabilitation patients. J Trauma. 1985; 25:419-23.

9. Buchholz A, Pencharz P. Energy expenditure in chronic spinal cord injury. Curr Opin Clin Nutr Metab Care. 2004;7:635-9.

10. Bauman WA, Spungen AM, Wang J, Pierson RN. The relationship between energy expenditure and lean tissue in monozygotic twins discordant for spinal cord injury. J Rehabil Res Dev. 2004;41:1.

11. Mollinger LA, Spurr GB, Ghatit AZ, Barboriak JJ, Rooney CB, Davidoff DD, et al. Daily energy expenditure and basal metabolic rates of patients with spinal cord injury. Arch Phys Med Rehabil. 1985;66:420-6.

12. Yilmaz B, Yasar E, Goktepe S, Alaca R, Yazicioglu K, Dal U, et al. Basal metabolic rate and autonomic nervous system dysfunction in men with spinal cord injury. Obesity. 2007;15:2683-7.

13. Aquilani R, Boschi F, Contardi A, Pistarini C, Achilli MP, Fizzotti G. Energy expenditure and nutritional adeauacy of rehabilitation paraplegics with asymptomatic bacteriuria and pressure sores. Spinal Cord. 2001;39:437-41.

14. Reeves MM, Capra S. Variation in the application of methods used for predicting energy requirements in acutely ill adult patients: A survey of practice. Eur J Clin Nutr. 2003;57:1530-5.

15. Reeves MM, Capra S. Predicting energy requirements in the clinical setting: are current methods evidence based? Nutrition Reviews 2003;61: 143-51.

16. Thibault-Halman G, Casha S, Singer S, Christie S. Acute management of nutritional demands after spinal cord injury. J Neurotrauma. 2011;28:1497-507.

17. Schofield W. Predicting basal metabolic rate, new standards and review of previous work. Hum Nutr Clin Nutr. 1985;39C(suppl 1): $0-5$.

18. Henry C. Basal metabolic rate studies in humans: measurement and development of new equations. Public Health Nutr. 2005;8:1133-52.

19. Buchholz AC, McGillivray CF, Pencharz PB. Differences in resting metabolic rate between paraplegic and able-bodied subjects are explained by differences in body composition. Am J Clin Nutr. 2003;77:371-8.

20. Nightingale TE, Gorgey AS. Predicting basal metabolic rate in men with motor complete spinal cord injury. Medicine \& Science in Sports \& Exercise. 2018;50:1305-312. 
21. Liusuwan A, Widman L, Abresch T, McDonald CM. Altered body composition affects resting energy expenditure and interpretation of body mass index in chiloren with spinal cord injury. $\mathbf{J}$ Spinal Cord Med. 2004;27:S24-S28.

22. Andersen RE, Sweet SN, Reid RER, Sydney F, Plourde H. Accuracy of two generic prediction equations and one populationspecific equation for resting energy expenditure in individuals with spinal cord injury. Can J Diet Pract Res. 2018;79:164-9.

23. Cunningham JJ. Body composition as determinant of energy expenditure: a synthetic review and a proposed general prediction equation. Am J Clin Nutr. 1991;54:963-9.

24. Chun SM, Kim HR, Shin HI. Estimating the basal metabolic rate from fat free mass in individuals with motor complete spinal cord injury. Spinal Cord. 2017;55:844-7.

25. Nelson KM, Weinsier RL, Long CL, Schutz Y. Prediction of resting energy expenditure from fat-free mass and fat mass. Am J Clin Nutr. 1992;56:848-56.

26. Schoeller DA, Racette SB. A review of field techniques for the assessment of energy expenditure. J Nutr. 1990;120:1492-5.

27. International Atomic Energy Agency. Assessment of body composition and total energy expenditure in humans using stable isotope techniques. IAEA Hum Heal. 2009;3.

28. Halliday D, Miller AG, Hallidayi D, Miller AG. Precise measurement of total body water using trace quantities of deuterium oxide. Biomed Mass Spectrom. 1977;4:82-87.

29. Davies PSW, Coward W, White G, Mills A. Total energy expenditure and energy intake in pre-school child: a comparison. Br J Nutr. 1994;72:13-20.

30. Weir J. New methods for calculating metabolic rate with special reference to protein metabolism. J Physiol L. 1949;109:1-9.

31. Wang Z, Deurenberg P, Wang W, Pietrobelli A, Baumgartner RN, Heymsfield SB. Hydration of fat-free body mass: Review and critique of a classic body-composition constant. Am J Clin Nutr. 1999;69:833-41.

32. Panisset MG, Desneves K, Ward LC, Rafferty J, Rodi H, Roff G, et al. Bedside quantification of fat-free mass in acute spinal cord injury using bioelectrical impedance analysis: a psychometric study. Spinal Cord. 2017;56:355-65.

33. Kocina PS, Heyward VH. Validation of a bioimpedance equation for estimating fat-free mass of spinal cord injured adults. Med Sci Sport Exerc. 1997;29:S55.

34. Harris JA, Benedict FG. A biometric study of human basal metabolism. Proc Natl Acad Sci. 1918;4:370-3.

35. McClave SA, Taylor BE, Martindale RG, Warren MM, Johnson DR, Braunschweig C, et al. Guidelines for the provision and assessment of nutrition support therapy in the adult critically ill patient: Society of Critical Care Medicine (SCCM) and American Society for Parenteral and Enteral Nutrition (A.S.P.E.N.). J Parenter Enter Nutr. 2016;40: 159-211.

36. Krenitsky J. Adjusted body weight, pro: evidence to support the use of adjusted body weight in calculating calorie requirements. Nutr Clin Pract. 2005;20:468-73.

37. Landis JR, Koch GG. The measurement of observer agreement for categorical data. Biometrics. 1977;33:159-74.

38. Bland JM, Altman DG. Statistical methods in medical research. Stat Methods Med Res. 1999;8:161-79.

39. Kruizenga HM, Hofsteenge GH, Weijs PJ. Predicting resting energy expenditure in underweight, normal weight, overweight, and obese adult hospital patients. Nutr Metab. 2016;13.

40. Nuhlicek DN, Spurr GB, Barboriak JJ, Rooney CB, Bongard RD. Rasmann body composition of patients with spinal cord injury. Eur J Clin Nutr. 1988;42:765-73. 